\title{
The Imagery Models of Mathematics Teacher Candidates on Graph of Rational and Irrational Functions
}

\author{
Darmadi \\ FKIP Universitas PGRI Madiun \\ Corresponding author: darmadi.mathedu@unipma.ac.id
}

\begin{abstract}
Students of mathematics teacher candidates are required to have good math and communication skills. Therefore, students of mathematics teacher candidates need to have good imagery modalities like the rational-irrational function graph. To get the imaginary student of mathematics teacher candidate in describing the rational-irrational function graph used qualitative research method. The subjects criteria are the students of mathematics education program, pursued the real course of analysis, and have not got the material to describe the rational-irrational function graph. The research data was taken by using the task test. The data were analyzed by categorizing, looking at the independence in describing, and looking at the logic or way of thinking. The research results showed that there are ten models (5 separate models and five combined models) of students' imaginary student of mathematics to the graph of a rational-irrational function. Mathematics lectures need to be emphasized to enrich students' imaginings on rational-irrational function graphs.
\end{abstract}

Keywords: imagery, teacher candidate, rational-irrational function,

\section{Introduction}

Imagery or student description of the function graph is needed in understanding the basic concepts of mathematics. To understand the concept of up, down, or constant function, the student needs to have an imagery or graphic picture of up, down, or constant function. To understand the concept of continuous function, students need to have a graphic imagery or graph of continuous function and non-continuous graphic functions. To understand the concept of derivative functions, students need to have a graph of function and graph of gradient or slope of function. To understand the integral concept, students need to have a graph of function, partition, supremum and infimum. This is in the opinion of Darmadi (2011) that imagery is very important in real analysis of learning.

One of the integral concepts is the Riemann integral. The Riemann integral concept is chosen in real-analysis because it is considered the easiest to learn and acceptable to students. From an understanding of the Riemann integral, students can distinguish between integrated functions and un-integral-able functions. A frequently used example for explaining Riemann's non-integrated functions is irrational. For that, the student needs to have an imagery or graphic picture of irrational function. According to the opinion of Darmadi (2012) that need to build a fun math learning with visualization. 
Imagery or graphic images need to be trained or inculcated for math teacher candidates. Darmadi (2015) study explains the importance and visual thinking process of prospective mathematics teacher students in understanding the definition. Darmadi (2016) study explains the importance and visual thinking process of mathematics teacher candidate in solving the problem. Students of mathematics teacher candidates are students who are designed to be math teachers. As a teacher, students of mathematics teacher candidates need to have good communication skills and math skills. To that end, the students of mathematics teacher candidates need to have good imagery or graphic picture. This paper discusses the imagery of the mathematics student candidate in describing the rational-irrational function graph.

This paper discusses the imaginary student of mathematics teacher candidate in describing the rational-irrational function graph. Visualization by Zimmermann \& Cunningham (1991) and Hershkowitz (1989) is the ability, process, and product of the creation, interpretation, use, and reflection of images, diagrams in mind, on paper or by technology for the purpose of describing and communicating information, thinking and developing ideas previously unknown. Borba \& Villarreal (Goos, et al, 2007) write that visualization is a two-way process between one's mind and the external media. Furthermore, Arcavi (2003) defines limited visualization on the use of numbers, drawings, and diagrams. That is, visualization is the use of images and diagrams to communicate information in the mind to external media.

The research problem is how many imaginary student of mathematics teacher candidate in describing the rational-irrational function graph. There are still no studies that focus on this. Studies about imagery in general are very common. The theory of David Tall, Van Hille, and several theories of the learning theory imply that visualization is important in learning mathematics. This research is important to know the imagery of students in learning modality as a Riemann integral. If this modality is not known, then it will happen within the constraints of the learning of real analysis. The lecturer will assume that students are able to learn when not to follow the learning difficulties and students. As a result, students contended that real analysis difficult.

Research results can indicate the existence of a certain model of imagery if students have never get the picture graph rational functions-irrational. If student already know or get, then it is possible there are not many models of imagery. The results of this research can be developed to know the richness of imagery students as a modality in learning mathematics.

\section{Research Methods}

To get the imaginary student of mathematics teacher candidate in describing the rational-irrational function graph used qualitative research method. This method is chosen because the focus and the results of the study is a description of student imagery taken based on natural data. The subjects of the study were students of mathematics education program of FKIP Universitas PGRI Madiun academic year 2017/2018 semester 7 who pursued real course of analysis and have not got the material to describe the rational-irrational function graph. There are 23 subjects participating in this activity.

The type of data that is obtained is a type of primary data obtained from observation and in-depth interview. The research data was taken by using the task test on the students to describe the following function graph.

$$
f(x)= \begin{cases}x, & x \text { rasional } \\ 1, & x \text { irrasional }\end{cases}
$$


Furthermore, students are asked to execute with the question why the picture like that? The data were analyzed by categorizing the subject's imagery in drawing the function graph, looking at the independence in describing, triangulation, and looking at the logic or way of thinking to get the subject graphic picture so that the conclusion about the imagination of the mathematics student candidate in the graph of the irrational rational function.

\section{Results and Discussion}

Based on the data obtained, the prospective mathematics student imaginary in describing the graph of irrational functions can be categorized as follows.

Separate model

Some students consider the given function to be two distinct functions that have two separate graphic image imagery. Here are the models of student imagery with a separate graphical picture.

Separate model 1

A separate model 1 given the subject of a candidate for mathematics teacher is showed in Figure 1.

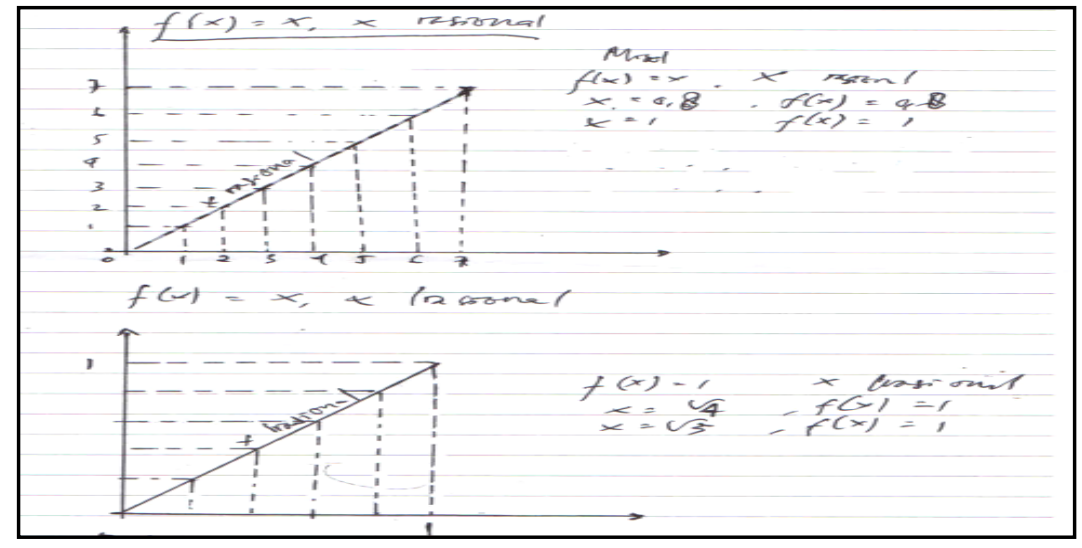

Figure 1. Separate Imagery Model 1

There are $7 \%$ respondents who provide this model. Students only plot for nonnegative domains (zero and positive). This shows that students are still fixated on non-negative domains only in describing the function graph. Students are less careful in paying attention to the definition of function so that the graphic image of the function for the irrational follows the function graph image for the rational. Students describe the graph of a given function in a separate form indicating that the student is not yet accustomed to finding graphic images of rational and irrational functions.

Separate model 2

Separate model 2 given subject of mathematics teacher candidate is presented in Figure 2. There are 13\% respondents who provide this model. Students have plotted for domain set of real numbers. However, students are less careful in paying attention to the definition of function so as to illustrate the graph of irrational functions inappropriately. In addition, students describe the graph of a given function in a separate form indicating that the student is not yet accustomed to finding graphic images of rational and irrational functions. 


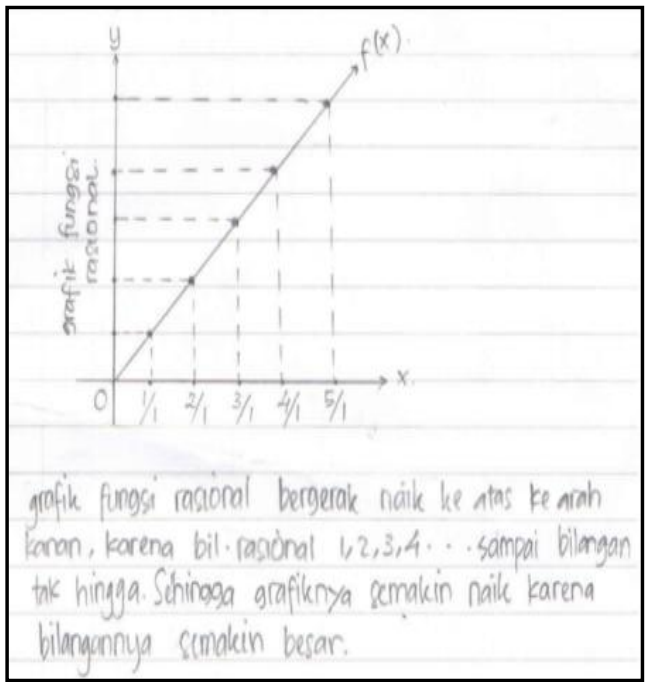

(a)

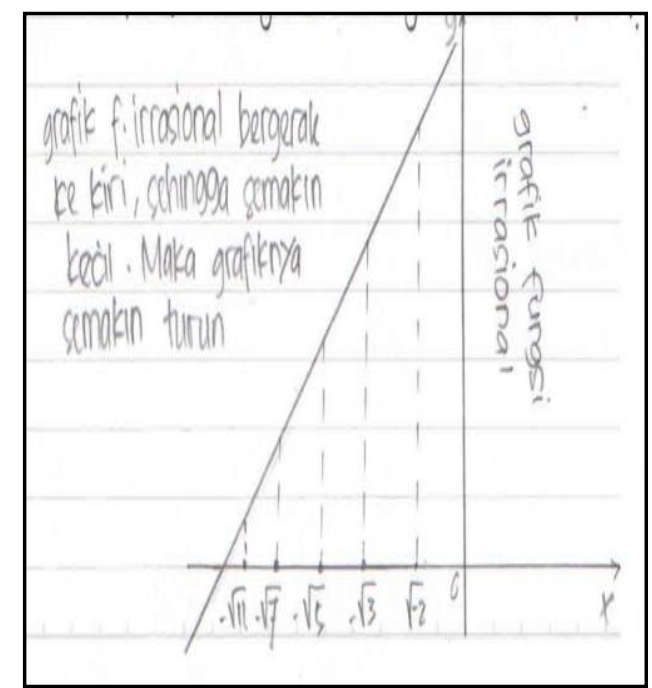

(b)

Figure 2. Separate Imagery Model 2

\section{Separate model 3}

A Separate model 3 given subject of mathematics teacher candidate is presented in Figure 3.

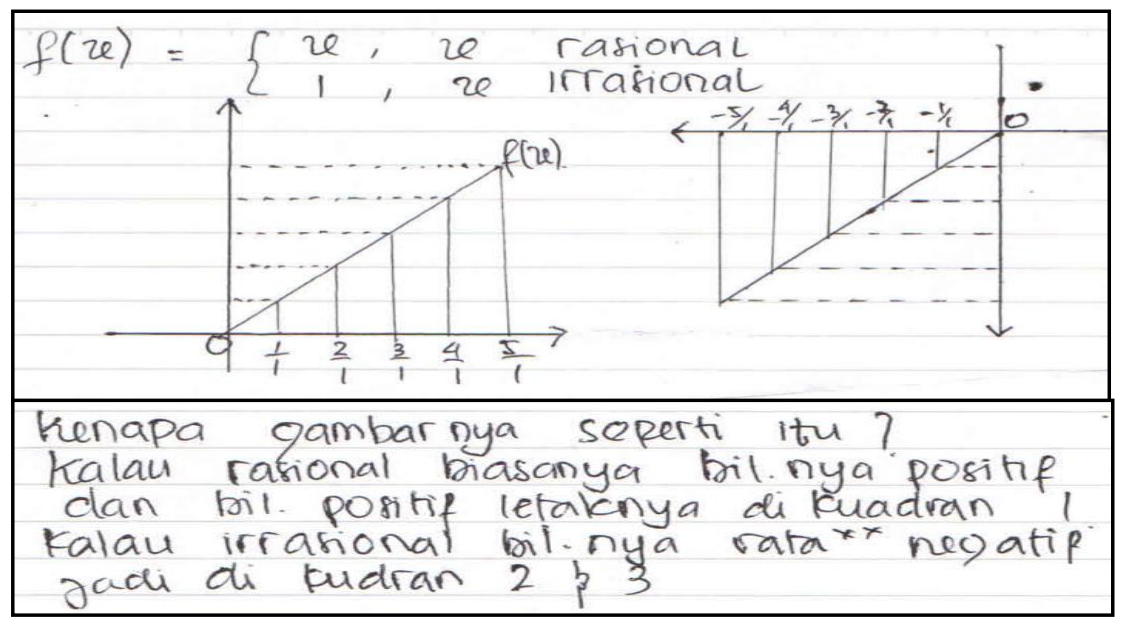

Figure 3. Separate Imagery Model 3

There are 4\% respondents who provide this model. Students have plotted for domain set of real numbers. This indicates that the students are not fixated on non-negative domain only in drawing. Students are less careful in distinguishing irrational rational by positive negatives. Students describe the graph of a given function in a separate form. Although rational and irrational numbers are different, they are dense in the set of real numbers. This indicates that the students are not accustomed to finding graphic images of rational and irrational functions.

\section{Separate model 4}

A Separate model 4 given the subject of mathematics teacher candidates is presented in Figure 4. There are 26\% respondents who provide this model. Students plot the function only for non-negative (zero and positive) domains. This shows that the students are still fixated on non-negative domains only in drawing. Students describe the 
graph of a given function in a separate form indicating that the student is not yet accustomed to finding graphic images of rational and irrational functions.

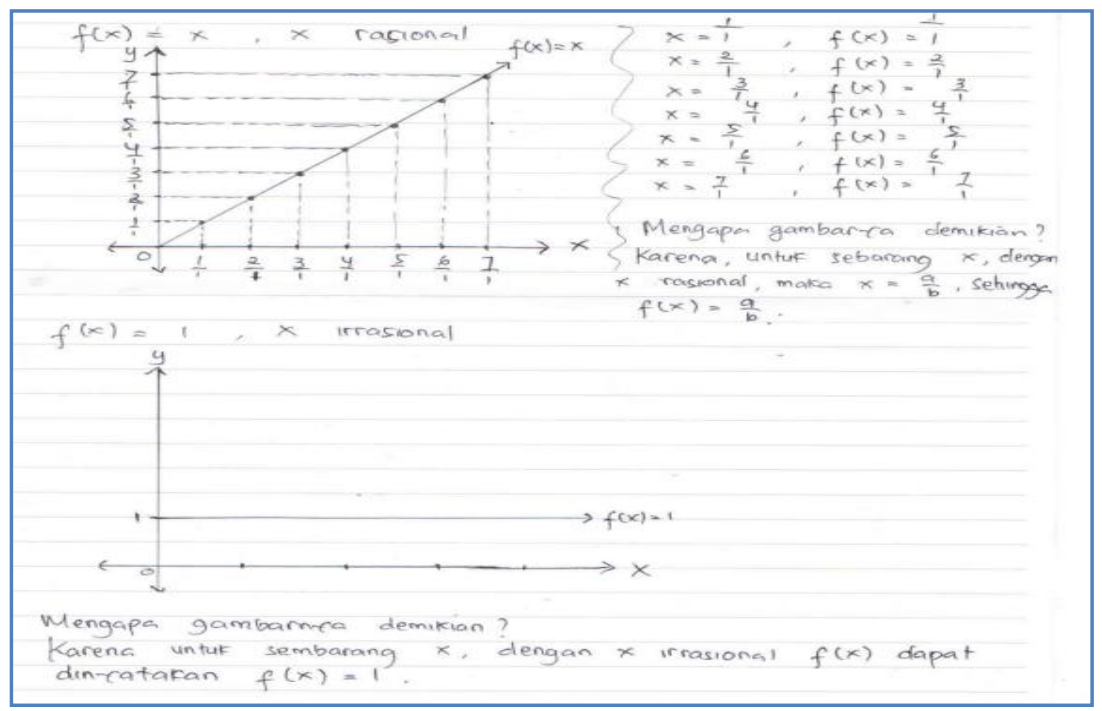

Figure 4. Separate Imagery Model 4

\section{Separate model 5}

A Separate model 5 given the subject of mathematics teacher candidates is sh owed in Figure 5.

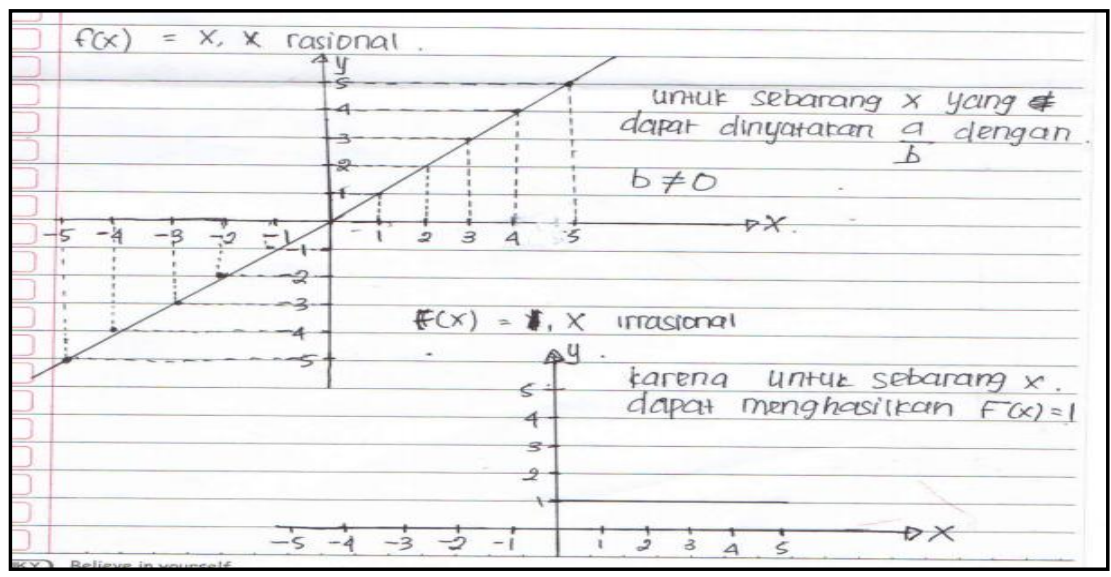

Figure 5. Separate Imagery Model 5

There are 7\% respondents who provide this model. Students have drawn graphic function graphs for the domain of real numbers. This indicates that the student has understood the agreement about the real function. Real functions are functions with domains and co domain set of real numbers. Unregulated functions of domain and co domain are agreed upon as real functions. Students describe the graph of a given function in a separate form. For irrational $x$, the plot of the function graph is still in the domain of the non-negative real number. This indicates that the students are not accustomed to finding graphic images of rational and irrational functions. 


\section{Combined model}

Some students have an imaginary or picture of a given function is a function so it does not have two separate graphic image imagery. Here are the models of student imagery with an inseparable graphical picture or join.

\section{Combined model 1}

Model 1 given the subject of mathematics teacher candidates is showed in Figure 6.

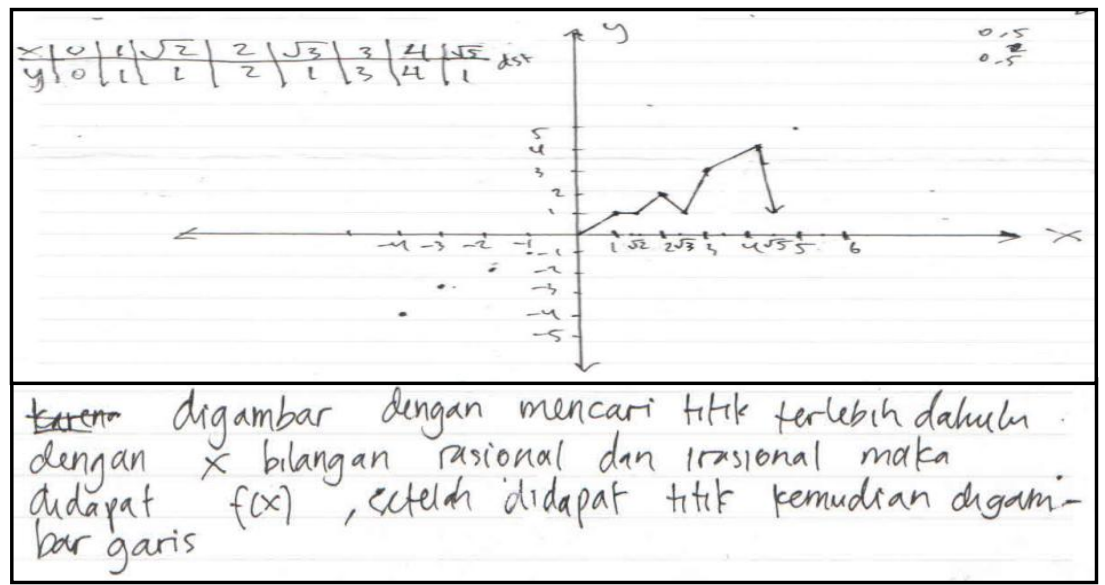

Figure 6. Imagery Model Combined 1

There are 4\% respondents who provide this model. The student plots the function graph provided for non-negative (zero and positive) domains. This shows that the students are still fixated on non-negative domains only in drawing. In addition, students are less careful in plotting because glued to the table so that the imagery or student graph picture is very less perfect.

\section{Combined model 2}

The combined model 2 given by the subject of the mathematics teacher candidate is presented in Figure 7.

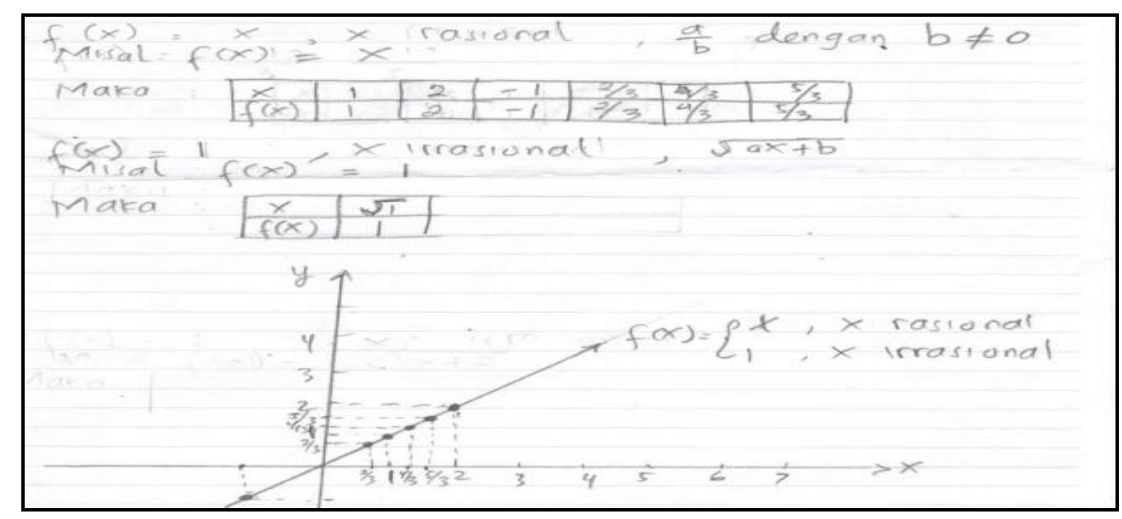

Figure 7. Imagery Model Combined 2

There are 4\% respondents who provide this model. Students have plotted for the domain of set of real numbers which indicates that the student has understood the agreement about the real function i.e. the function which is not written domain and the co domain agreed as the real function. Students are less careful in paying attention to the 
definition of function so that the graphic image of the function for the irrational $x$ follows the function graph image for the rational $x$.

\section{Combined model 3}

The combined model 3 given by the subject of the mathematics teacher candidate is as follows.

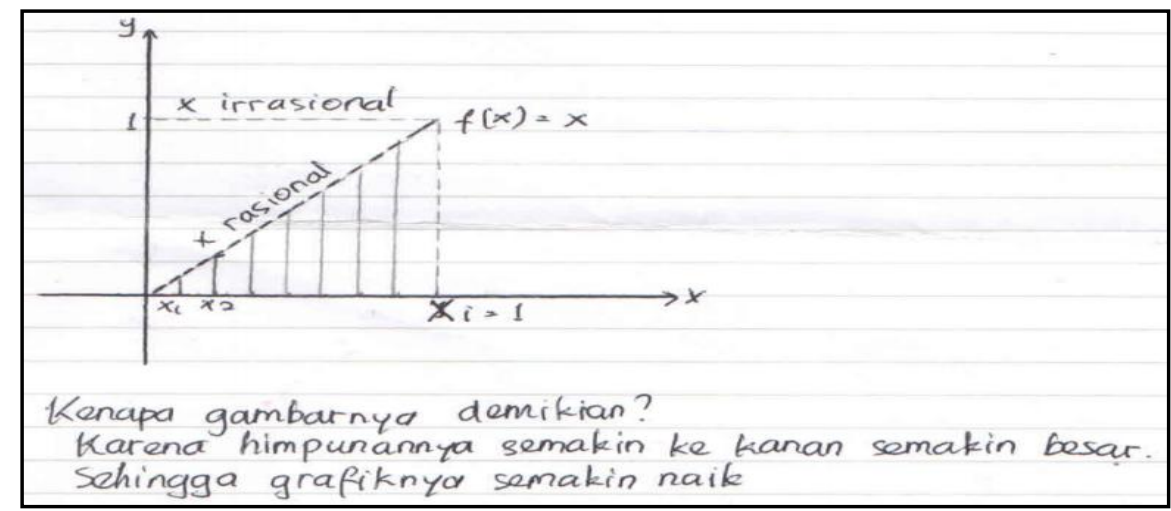

Figure 8. Imagery Model Combined 3

There are $22 \%$ respondents who provide this model. Students plot only for non-negative (zero and positive) domains. It's indicating that the student has not understood the agreement about the real function. It can also show that students are still fixated on nonnegative domains only in a drawing. The arguments given by the students are not in accordance with the concept of the given function definition.

\section{Combined model 4}

The combined model 4 given by the subject of the mathematics teacher candidate is showed in Figure 9.

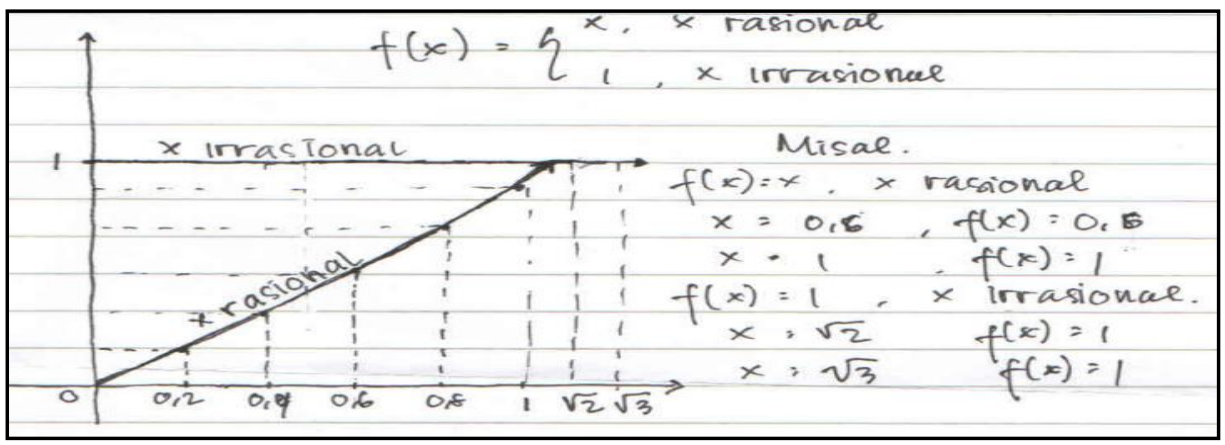

Figure 9. Imagery Model Combined 4

There are 4\% respondents who provide this model. Students plot the function only for non-negative (zero and positive) domains. In strokes it appears that the student only takes into account for positive $x$ values. This shows that the students are still fixated on non-negative domains only in drawing. In addition, the student is less careful in plotting because for $x=1$ (rational) the value of $f(x)$ should also be 1 (from the definition for the rational $\mathrm{x}$ of the value $f(x)=x$ ). But in the picture (as an imaginary representation), it appears that the value of $f(1)$ is below 1 (not $f(1)=1$ ). The accuracy or thoroughness of students in shaping the imagery or graph of functional features needs to be developed. 


\section{Combined model 5}

The combined model of 5 subjects given by mathematics teacher candidates is presented in Figure 10.

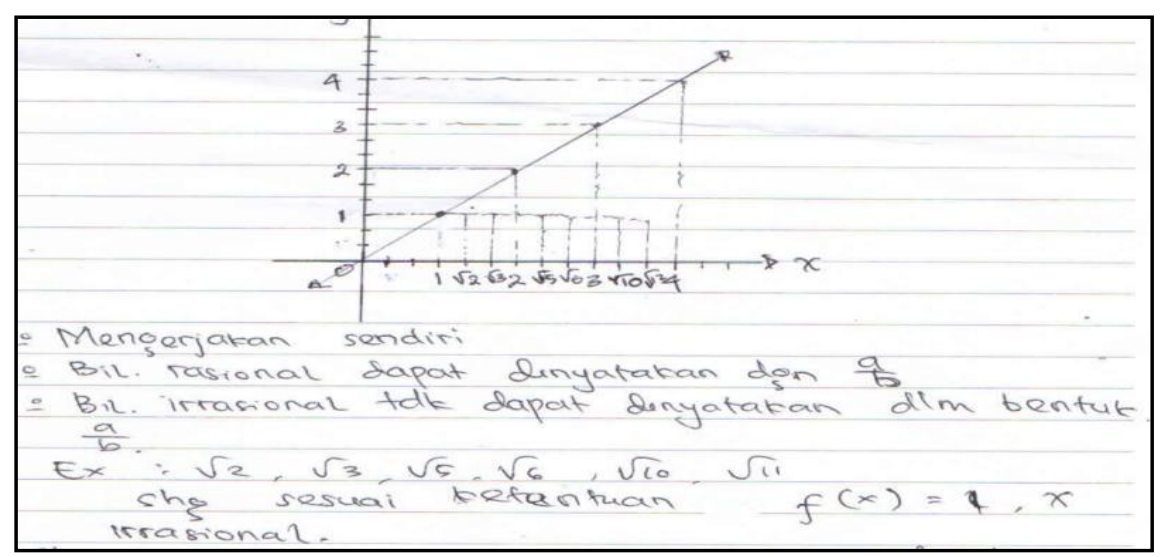

Figure 10. Imagery Model Combined 5

There are 4\% respondents who provide this model. Students plot the function only for non-negative (zero and positive) domains. It is indicating that students are still fixated on non-negative domains just in a drawing. Besides, students are less careful in paying attention to the definition of function so that the graphic image of the function for the irrational $\mathrm{x}$ follows the function graph image for the rational $x$.

Regardless of right or wrong answers to the student, imagery is essential in learning mathematics (Tall, 2007). If the imagery is false, make understanding students also wrong. If the Imagery is right, constructive understanding a student's right. It happens because the imaging is forming the concept image, a description of the concept (Tall and Vinner d. s., 1981). Concept is the mental representation of a thing or class of things so that an individual can decide whether a specific stimulus is an instance of that object or class of objects and act on the basis of that judgment (Matsumoto. D, 2009).

\section{Conclusion}

Based on the result of data analysis, it can be concluded that the mathematics teacher candidate imagination in drawing the irrational function graph can be categorized in two models, namely: separate and combined models. Each models is covering 5 models so that there are 10 models of mathematics teacher candidate against the rational-irrational function graph.

Based on the conclusions, lecturers to be better provide students understanding of rational and irrational numbers. Many things that need to be considered by lecturers to improve the quality and wealth of students' imaginations of mathematics teachers. Lecturers should not be too focused on formalities but also need to explain by using pictures or graphs.

\section{Bibliography}

Arcavi, A. (2003). The Role of Visual Representations in the Learning of Mathematics. Educational Studies in Mathematics, 52 (3) pp.215-240.

Darmadi. (2011). Imagery Students in Learning Real Analysis (case study at IKIP PGRI Madiun). Paper Presented at the National Seminar of UNY, Jogjakarta, December 3,2011 
Darmadi. (2012). Build Congenial Learning Mathematics with Visualization. Paper presented at the National Seminar of UNY, Jogjakarta, 24 March 2012

Darmadi. (2015). Visual Thinking Student Profiles of prospective teachers of mathematics in understanding the Formal definition based on Gender differences. Dissertation, UNESA, Surabaya

Darmadi. (2016). Visual Thinking Student Profiles of prospective teachers of mathematics in solving Trigonometric Problems, Journal of Math Educator, ISSN: 2459-97345, Volume 2 number 2, pp. 1-93, may 2016, Math Education Courses, FKIP Universitas Nusantara PGRI Kediri

Goos, M., Stillman, G. Dan Vale, C. (2007). Teaching Secondary School Mathematics Research and Practice for the 21st Century). Australia: Allen \&Unwin.

Hershkowitz, R. (1990). Psychological aspects of learning geometry, in P. Nesher, J. Kilpatrick (Eds.), Mathematics and Cognition. A Research Synthesis by the International Group for the Psychology of Mathematics Education, ICMI Study Series, Cambridge University Press, pp. 70-95.

Matsumoto. D, (2009). The Cambridge Dictionary Of Psychology. San Francisco State University. Cambridge University Press 2009

Richard R. Goldberg. (1964). Methods of Real Analysis. The University of Lowo. John Wiley \& Sons, Inc. New York, Londin, Sydney, Toronto, pp 183

Tall D. and Vinner S. (1981). Concept image and concept definition in Mathematics with particular reference to Limits and continuity Educational Studies in Mathematics 12 (1981) 151-169. Copyright by D. Reidel Publishing Co., Dordrecht, Holland, and Boston, U.S.A.

Tall. (2007). Embodiment, Symbolism And Formalism In Undergraduate Mathematics Education. Keynote presented at the 10th Conference on Research in Undergraduate Mathematics Education, Feb 22-27, 2007, San Diego, California, USA.

Tall. (2013). How Humans Learn to Think Mathematically. Cambridge University Press: New York.

Zimmermann, W. and Cunningham, S. (2011). Editors Introduction: What is Mathematical Visualization. In W. Zimmermann and Cunningham (eds), Visualization in Teaching and Learning Mathematics. Mathematical Association of America. Washington DC. pp. 1-8. 